\title{
TEORETSKA IZHODIŠČA IN METODOLOŠKI OKVIR \\ PRI IZDELAVI UPORABNIKOM PRIJAZNEGA \\ SPLETIŠČA: PRIMER PLATFORME SMeJse - \\ SLOVENŠČINA KOT MANJŠINSKI JEZIK
}

\author{
Matejka GRGIČ \\ Slovenski raziskovalni inštitut SLORI
}

Grgič, M. (2017): Teoretska izhodišča in metodološki okvir pri izdelavi uporabnikom prijaznega spletišča: primer platforme SMeJse - Slovenščina kot manjšinski jezik. Slovenščina 2.o, 2017 (2): 85-112.

DOI: http://dx.doi.org/10.4312/slo2.0.2017.2.85-112.

V prispevku predstavljam teoretska in metodološka izhodišča za izdelavo portala SMeJse (Slovenščina kot manjšinski jezik), ob tem pa se obsežneje zaustavljam ob analizi položaja, stanja in statusa slovenskega jezika v Italiji, nekaterih specifičnih jezikovnih pojavih, metodoloških izzivih in socioloških okvirih.

Pojmi, kot so zvrstnost jezika, norma, prvi/materni oz. tuji jezik, manjšina, diglosija in številni drugi izgubljajo namreč pomen, ki so ga imeli v epistemologijah 20. stoletja, in pridobivajo nove konotacije. Do teh ključnih premikov pri obravnavi jezikovnih pojavov in načrtovanju jezikovnih politik prihaja zaradi novih družbenih kontekstov ob prehodu iz 20. v 21. stoletje. Na percepcije in reprezentacije jezika, ki močno pogojujejo njegovo usvajanje, rabo in uradni položaj - pa tudi znanstveno obravnavo -, vplivajo nekateri »zunanji « dejavniki. Med temi gre izpostaviti razvoj in dostopnost novih tehnologij, evropsko politiko na področju manjšinskih jezikov in večjezičnosti nasploh, ekonomsko krizo in njene posledice ter migracijske tokove. Pojmovanje »manjšine« in »manjšinskosti « je tudi na področju jezika in jezikoslovja dobilo nove in drugačne razsežnosti.

Na podlagi teh ugotovitev sta Slovenski raziskovalni inštitut (SLORI) in Dijaški dom S. Kosovela v Trstu izdelala spletno platformo SMeJse (www.smejse.it) kot zbirališče novih in že obstoječih orodij, gradiv in informacij za razvoj jezikovnih 
veščin in spretnosti v slovenskem jeziku. Namen platforme je spodbujanje različnih rab živega slovenskega jezika na območju italijansko-slovenskega jezikovnega stikanja, predvsem v Italiji - s ciljem, da se zagotovi visoka sporazumevalna zmožnost $\mathrm{v}$ vseh zvrsteh in različicah slovenskega jezika, uravnotežena dvojezičnost in razvoj tudi lokalnih idiomov, a znotraj slovenskega jezikovnega kontinuuma.

Ključne besede: manjšinski jeziki, slovenščina $\mathrm{v}$ Italiji, razvoj jezikovnih veščin, uravnotežena dvojezičnost, jezikovni stik

\section{UVOD}

Ob raziskovanju različnih vidikov in pojavov slovenskega jezika v Italiji (Carli, Sussi, Kaučič Baša 2002; Mezgec 2012; Jagodic, Čok 2013; Vidau 2013; Pertot, Kosic 2014; Bogatec 2015; Grgič 2017), pa tudi ob soočanju z govorci slovenskega jezika $\mathrm{v}$ Italiji ter organizacijami, ustanovami in šolami $\mathrm{s}$ slovenskim učnim jezikom na tem območju, je bil oblikovan projekt Spodbujanje razvoja jezikovnih veščin za potrebe sporazumevanja $\mathrm{v}$ slovenskem jeziku, ki ga je sofinanciralo Ciljno začasno združenje Projekt. V sklopu projekta je bila $\mathrm{v}$ tem letu mdr. izdelana spletna platforma SMeJse (Slovenščina kot manjšinski jezik; www.smejse.it) kot zbirališče novih in že obstoječih orodij, gradiv in informacij za razvoj jezikovnih veščin in spretnosti v slovenskem jeziku. Namen platforme je spodbujanje različnih rab živega slovenskega jezika na območju italijansko-slovenskega jezikovnega stikanja, predvsem v Italiji - s ciljem, da se zagotovi visoka sporazumevalna zmožnost v vseh zvrsteh in različicah slovenskega jezika, uravnotežena dvojezičnost in razvoj tudi lokalnih idiomov, a znotraj slovenskega jezikovnega kontinuuma.

V nadaljevanju izrecno predstavljam izhodišča, metodologije in pričakovane rezultate projekta, nato pa se v obsežnejšem razdelku zaustavljam ob nekaterih teoretskih in metodoloških izzivih. Vsebino spletne platforme bom predstavila v drugem kontekstu. 


\section{IZHODIŠČA}

Sistem ocenjevanj in klasifikacij položaja, statusa, percepcije, obdelave in ravni znanja jezikov je že več let predmet ponovne kritične obravnave (MacIntyre et al. 1997; Grgič 2016b). Dosedanji teoretski okviri, ki so zaznamovali intra- in interdisciplinarne jezikoslovne vede 20. stoletja (Formigari 2001), se ob prehodu v 21. stoletje vsaj spreminjajo, če že ne rušijo. Nove stvarnosti globalizacija in migracije, virtualni svetovi in nove tehnologije nas postavljajo tudi pred drugačne epistemološke izzive (Canagarajah 2005). Prav tako se je v zadnjih desetletjih bistveno spremenila slika t. i. manjšinskih jezikov - vsaj znotraj EU in pravnega reda držav članic (Coulmas 1991; Phillipson 2003). Pojmi, kot so zvrstnost jezika, norma, prvi/materni oz. tuji jezik, manjšina, diglosija in številni drugi izgubljajo pomen, ki so ga imeli v epistemologijah 20. stoletja, in pridobivajo nove konotacije. Na področju obravnave manjšinskih jezikov v praksi na primer lahko postavimo hipotezo, da pridobljene pravice določene (manjšinske) skupnosti in urejen status (manjšinskega) jezika nista vedno porok za splošno »znanje « tega jezika, slednje pa ni nujno zadosten pogoj za razvoj veščin, ki bi govorcem omogočale učinkovito, uspešno in suvereno rabo manjšinskega jezika $\mathrm{v}$ potencialno vseh sporazumevalnih okoliščinah (Thordardottir 2011). Nova slika odnosov med statusom, znanjem in dejansko rabo jezika (s poudarkom na slednji) je spremenila epistemološki okvir in s tem kontekstualizacijo temeljnih strokovnih pojmov - med temi je na primer tudi pojem diglosije, ki ga obravnavam v nadaljevanju.

Ob ustreznem razlikovanju med jezikovnimi znanji, spretnostmi in veščinami danes ugotavljamo, da samo učenje jezika (torej pridobivanje znanj $\mathrm{v}$ didaktično strukturiranih okoljih, npr. v šolah) ni zadosten pogoj za razvoj spretnosti in veščin, ki so nujne za uspešno in suvereno sporazumevanje $\mathrm{v}$ danem jeziku $\mathrm{v}$ potencialno vseh kontekstih njegove rabe. Nerazvitost jezikovnih spretnosti in veščin pa še izraziteje kot pomanjkanje znanj prispeva $\mathrm{k}$ (samo)izključevanju govorcev in praks in procesov, kjer ti elementi ključno prispevajo k uspehu komunikacijskih interakcij med osebami in skupinami - 
na primer iz procesov odločanja, pogajanja, argumentiranja (Myhill, J., 2003; Van Dijk 2008). To lahko vodi do marginalizacije govorcev in posledično do socialnih in ekonomskih neenakosti, izločevanja in celo nasilja nad »Šibkejšimi « osebami in skupinami, ki so v tem primeru tiste z manj razvitimi jezikovnimi spretnostmi in veščinami v danem jeziku (Piller 2016). Ta proces, ki se je v sociolingvistiki 20. stoletja obravnaval predvsem na relaciji večinski (dominantni) jezik - manjšinski (podrejeni) jezik, se danes vzpostavlja tudi na drugi relacijah, na primer znotraj kontinuuma manjšinskega jezika med njegovim centrom in skrajno periferijo oz., če povzamemo z značilnim diskurzom za slovenski prostor, med matico in zamejstvom. Ta vidik novega »manjšinjenja « podrobneje obravnavam v razdelku 4.2.

Nerazvitost jezikovnih veščin in sporazumevalnih spretnosti lahko privede tudi do uporabe izključno lokalnih različic ali do ustvarjanja vzporednih standardov in, $\mathrm{v}$ končni fazi, do novih jezikovnih mešanic, ki postanejo edini sporazumevalni standard skupnosti (Trudgill 2004). Tam, kjer se skupnost identificira z jezikom, lahko predstavlja neuravnoteženo razvijanje skoraj izključno lokalnih idiomov - tudi mešanic - začetek procesov t. i. jezikovnega secesionizma oz. separatizma (prim. razdelek 4.3).

Nazadnje je lahko pomanjkljiva zavest o jezikovnih pojavih prostor za nastanek in razvoj novih ideoloških jeder (Tollefson 2000), ki samo še zavirajo procese promocije, rabe in s tem razvijanja jezika v nekem okolju.

\section{METODOLOGIJA DELA}

Projekt SMeJse temelji na spodbujanju usvajanja jezika $\mathrm{s}$ (spletnim) izpostavljanjem govorcev različnim kodom, idiomom in variantam danega jezikovnega kontinuuma. Izhajamo namreč iz metodološke predpostavke, da se jezikovne spretnosti in veščine ne razvijajo izključno $\mathrm{z}$ učenjem jezika $\mathrm{v}$ didaktično strukturiranem okolju (torej v šolah ali na tečajih), ampak predvsem s spontanim usvajanjem jezika, torej z izpostavljenostjo raznolikosti jezikovnih praks (Thordardottir 2011). Zato je nujno, da se ta izpostavljenost v okoljih, kjer 
je omejena ali kako drugače sporna ali pomanjkljiva, podkrepi z ustreznimi orodji. Nadalje je nujno, da se izpostavljenost različnim rabam prenese tudi v didaktično strukturirana okolja: v prostoru, kjer je dani jezik manjšinski oz. neprevalenten, se morajo ustvariti dodatni pogoji za spontano usvajanje jezika in posledično razvijanje potrebnih sporazumevalnih veščin in spretnosti.

Obenem ugotavljamo, da je predpostavka, da šole z manjšinskim učnim jezikom same po sebi nudijo možnost učenja po sistemu t. i. popolne potopitve oz. jezikovne kopeli, neustrezna in do določene mere ideološko pogojena. Raziskave, opravljene v drugih okoljih (Hickey 2001), namreč dokazujejo, da tovrstne šole - ob pomanjkanju drugih in dodatnih ukrepov za ustvarjanje potrebe po splošni rabi manjšinskega jezika tudi $\mathrm{v}$ neformalnem sporazumevanju - ne zagotavljajo ustrezne izpostavljenosti učnemu jeziku.

Iz vseh zgoraj omenjenih ugotovitev že nekaj desetletij izhajajo snovalci učnih gradiv in orodij za učenje in poučevanje tujih jezikov (Meisel 2007; Cook 2008; Schmidt 2010). Metodologija didaktike manjšinskih jezikov pa se vsaj do določene mere še vedno opira na povsem ideološkega izhodišča, da je manjšinski jezik obenem »materni« oz. prvi jezik (J1) učencev in dijakov, pa tudi prevalentni jezik njihovega okolja (Unsworth 2014) - z drugimi besedami: manjšinski jezik naj bi bil primarni sporazumevalni kod (vseh) pripadnikov skupnosti, ki se s tem jezikom identificira. Tej vsaj delno apriorni in ideološki percepciji umestitve manjšinskega učnega jezika v jezikovni horizont učencev in dijakov se prilagajajo tudi didaktične metode, ki sledijo splošnim smernicam s področja poučevanja/učenja prvih (»maternih «) jezikov v okoljih, kjer so ti jeziki prevalentni.

Nenazadnje gre upoštevati še dejstvo, da je t. i. komunikacijski pristop pri pouku (prvega) jezika v italijanskem sistemu manj pogost kot v slovenskem. Zaradi različne ureditve šolskega področja je $\mathrm{v}$ učnih načrtih nekoliko več prostora namenjenega učenju slovnice in pravopisa, še zlasti pa književnosti (Strani 2017). Snovalci ministrskih smernic so očitno izhajali iz modela 
večinskega učnega jezika in posledično iz prepričanja, da lahko italijansko govoreči učenci in dijaki, ki izhajajo iz italijansko govorečih družin in živijo $\mathrm{v}$ italijanskem jezikovnem okolju, spontano razvijajo svoje jezikovne veščine in sporazumevalne zmožnosti $\mathrm{v}$ tem jeziku - te veščine in sposobnosti nato $\mathrm{v}$ šoli le še nadgradijo. Predpostavka, ki je bila smiselna v kontekstu modela »jezik družine $=$ jezik okolja $=$ jezik šole $«$, pa postane ob vključitvi ene same spremenljivke že sporna.

Pilotna empirična analiza stanja in potreb je na primer pokazala, da za razvijanje sporazumevalne zmožnosti v slovenskem jeziku na naselitvenem območju slovenske manjšine v Italiji potrebujemo nov didaktični model, ki ne bo ideološko enačil »maternosti« jezika s stopnjo njegovega znanja, predvsem pa ne s stopnjo razvitosti sporazumevalnih spretnosti in veščin (Davies 2003). V sklopu projekta smo torej kombinirali metodologije poučevanja/učenja tujih ali drugih jezikov $\mathrm{z}$ metodologijami poučevanja prvih jezikov in $\mathrm{z}$ metodologijami razvijanja sporazumevalnih spretnosti in veščin, ki izhajajo $\mathrm{s}$ področij komunikologije in retorike.

Predvsem pa smo didaktični model uporabili tudi v okoljih, ki niso didaktično strukturirana. Ko govorimo o didaktiki, na splošno razmišljamo o šoli oz. o izobraževalnih ustanovah nasploh. V okviru projekta pa smo želeli ustvariti platformo, s katere bi lahko do orodij, virov in primerov dobre prakse dostopali vsi govorci slovenskega jezika v Italiji - ne glede na okolje, v katerem jezik uporabljajo, usvajajo in se ga učijo, ter ne glede na stopnjo znanja oz. razvoja veščin v tem jeziku.

\section{CILJI}

Ključni predvideni rezultat projekta je vzpostavitev spletne platforme SMeJse, ki bo namenjena predvsem govorcem slovenskega jezika v Italiji. Končni cilj projekta je zagotavljanje visoke sporazumevalne zmožnosti v vseh zvrsteh in različicah slovenskega jezika, doseganje uravnotežene dvojezičnosti in razvoj tudi lokalnih idiomov, a znotraj slovenskega jezikovnega kontinuuma. 


\section{IZZIVI TEORETSKIH IZHODIŠC̆ IN METODOLOŠKIH OKVIROV PROJEKTA SMEJSe}

Platforma SMeJse bo uporabnikom prijazno, inovativno spletišče, ki bo omogočalo čim bolj intuitivno, preprosto in hitro uporabo, po drugi strani pa tudi sprotno posodabljanje, dopolnjevanje in urejanje vsebin. SMeJse naj bi bil spletni prostor, ki bi uporabnikom zagotavljal zadostno in ustrezno izpostavljenost različnim rabam slovenskega jezika, ki je sicer $\mathrm{v}$ svojem fizičnem prostoru niso deležni. Kljub intuitivnosti, preprostosti in prijaznosti pa je vzpostavitev spletne platforme postavljala (in še postavlja) celo vrsto teoretskih in metodoloških izzivov, ki bi jih lahko povzeli z motom »trenje ideoloških jeder« ali »podiranje lažnih mitov«. V nadaljevanju predstavljam nekaj takih epistemoloških in metodoloških vozlišč.

\subsection{Diglosija}

Do nedavnega se je diglosija obravnavala skoraj izključno kot nepoznavanje »višjih « zvrsti jezika (Kaučič-Baša 1997), ki je bilo predvsem posledica dejstva, da se pripadniki manjšinskih skupnosti niso šolali v svojem prvem/družinskem jeziku oz. da tega jezika niso uporabljali $\mathrm{v}$ formalnih okoljih ali $\mathrm{v}$ javnosti nasploh - zaradi bolj ali manj eksplicitnih prepovedi, stigmatizacij ali strahu pred fizičnim nasiljem. ${ }^{1}$ Klasična diglosija, ki je bila predmet sociolingvističnih raziskav v drugi polovici 20. stoletja, je sicer izhajala iz Fergussonove ugotovitve (Fergusson 1959), da imajo znotraj dane skupnosti govorcev nekatere zvrsti »nižji « $(\mathrm{L}=$ low $)$, druge pa »višji « $(\mathrm{H}=$ high $)$ status. To predpostavko je nato predelal J. Fishmann, ki je o diglosiji govoril tudi na ravni odnosov med dvema ločenima jezikovnima kontinuumoma (Fishmann 1967). Diglosija je tako postala ena ključnih tem pri analizi odnosov med manjšinskimi (običajno podrejenimi) in večinskimi (običajno dominantnimi) jeziki: raziskave, opravljene $\mathrm{v}$ drugi polovici 20. stoletja, so pokazale, da je za

\footnotetext{
${ }^{1} \mathrm{Z}$ diglosijo na primeru slovenskega jezika v Italiji se je največ ukvarjala M. Kaučič-Baša, ki je pojem tudi uvedla za preučevanje statusa in položaja jezika na območju poselitve slovenske narodne manjšine v Italiji (prim. Kaučič-Baša 1997).
} 
manjšinske/podrejene L-jezike značilna uporaba $\mathrm{v}$ domačem ali res neformalnem okolju, redko $\mathrm{v}$ javnosti; raba teh jezikov naj bi bila nadalje pogosto omejena le na ustno sporočanje. Zaradi vsega tega je razvoj L-jezikov okrnjen - vsaj v tistih skupnostih govorcev, ki dani jezik uporabljajo $\mathrm{v}$ omejenem spektru okoliščin. V nadaljnjih fazah lahko diglosija privede do pešanja (attrition) L-jezika in njegovega postopnega opuščanja vse do popolne izgube (loss) in zamenjave (shift) s H-jezikom. V primerih, ko je L-jezik regionalni jezik, ki nima nikjer statusa uradnega/državnega jezika oz. ni nikjer prevalenten sporazumevalni kod, ${ }^{2}$ to dejansko pomeni, da se celotni jezikovni kontinuum zreducira na raven folklornega idioma. V primerih, ko je L-jezik sporazumevalni kod narodne manjšine in je torej v podrejenem položaju le na določenem območju, medtem ko ima drugje status uradnega/državnega jezika oz. prevalentnega sporazumevalnega koda, zadeva diglosija le določeno skupino govorcev in ne celotnega jezikovnega kontinuuma.

Že ti dve razliki v »klasičnem « pojmovanju diglosije nam kažeta, da gre v resnici za izjemno kompleksen pojav (Saxena 2014), ki je v določenih primerih vsaj delno prekriven $\mathrm{z}$ drugimi $-\mathrm{v}$ nekaterih primerih bi bilo na primer bolj kot o diglosiji smiselno govoriti o neenakomernem razvoju jezika, neuravnovešeni ali neekvivalentni dvojezičnosti3 in o dediščinskem idiomu. 4

\footnotetext{
${ }_{2} \mathrm{Na}$ take primere so se osredotočile prve raziskave diglosije, pa tudi kasneje se je pojem uporabljal najpogosteje ob primeru regionalnih in ne nacionalnih jezikov.

$3 \mathrm{~S}$ strokovnima terminoma neuravnovešena vs. neekvivalentna dvo- in večjezičnost želim izpostaviti dve načeli »merjenja « sporazumevalne zmožnosti dvo- in večjezičnih govorcev. $\mathrm{V}$ primeru neuravnovešene dvojezičnosti govorimo o odnosu med večinskim in manjšinskim jezikom nekega območja: sporazumevalna zmožnost govorca je po navadi bolj razvita v enem od teh dveh jezikov. V primeru neekvivalentne dvojezičnosti pa govorimo o enem jeziku in primerjamo sporazumevalno zmožnost govorcev, ki živijo na območju, kjer je ta jezik prevalenten/dominanten, in o govorcih, ki živijo na območjih, kjer je ta jezik manjšinski oz. neprevalenten.

${ }_{4} \mathrm{~S}$ strokovnim terminom dediščinski jezik (heritage language) se označujejo različni jeziki, ki niso prevalentni (večinski, dominantni, uradni ...) v dani regiji. Dediščinski jeziki so nadalje običajno jeziki potomcev migrantskih skupnosti, ki jezik ohranjajo le še v specifičnih kontekstih, ne pa za potrebe vsakdanjega sporazumevanja - včasih niti v domačem okolju ne. Kljub temu pa imajo dediščinski jeziki med skupnostjo govorcev visok položaj kot identitetni simboli. Prim. Benmamoun, Montrul, Polinsky 2010, Van Deusen-Scholl 2003 in Kelleher 2010.
} 
Danes opažamo še drugačne in nove oblike diglosij, neekvivalentne dvojezičnosti in neustreznega razvoja sporazumevalne zmožnosti $\mathrm{v}$ manjšinskem jeziku (Pertot 2011a, 2011b). V nasprotju s preteklostjo namreč govorci L-jezika ponekod paradoksalno poznajo samo »višje« zvrsti tega jezika, saj se ga učijo predvsem ali izključno v šoli oz. so mu izpostavljeni le v formalnih sporazumevalnih okoliščinah; po drugi strani pa tem istim govorcem primanjkuje stik z različnimi neformalnimi, vsakdanjimi sporazumevalnimi okoliščinami, v katerih bi lahko uporabljali različne idiome, zvrsti in sloge tudi »nelokalnih" različic jezika (Pertot-Kosic 2014; Bogatec 2015). Z drugimi besedami: opažamo, da je formalna izobrazba sicer nujen, ne pa tudi zadosten pogoj za uspešno in učinkovito usvajanje nekega jezika (Cooper 1989; Cummins 1989; Hickey 2001). To je še posebej očitno $\mathrm{v}$ trenutku, ko govorimo o kontekstih, kjer je določeni jezik manjšinski oz. neprevalenten sporazumevalni kod - kjer torej govorci niso ustrezno ali v zadostni meri izpostavljeni različnim rabam tega jezika (Saxena 2014).5

Iz raziskav, ki so bile opravljene na naselitvenih območjih različnih vrst manjšin, ${ }^{6}$ izhaja, da so za spodbujanje tovrstnega razvoja potrebne specifične jezikovne politike in prakse, predvsem na področju didaktike manjšinskega jezika (Valdes 1997; Hickey 2001). Percepcija, da je manjšinski jezik tudi prvi in s tem primarni jezik (večine) učencev in dijakov, je namreč lahko povsem nerealna in ideološko motivirana - če je že kdaj veljala v preteklosti, danes mogoče ne velja več (Baker 2003; Bogatec 2004). Prav tako mogoče danes ne velja več, da je manjšinski jezik nujno prevalenten v okolju, iz katerega učenci

\footnotetext{
5 Vprašamo se seveda lahko, ali se niso ti pojavi že uveljavljali tudi v drugi polovici 20. stoletja, le da so bili takrat še zamolčani, saj so se raziskave podrejale ideološkim predpostavkam, ki v določeni meri veljajo še danes in dejansko onemogočajo uspešno implementacijo novih modelov promocije, usvajanja in raziskovanja jezikov.

${ }_{6}$ Poznamo različne vrste manjšinskih skupnosti; na podlagi statusa in položaja jezika ter različnih jezikovnih pojavov jih na splošno lahko delimo na narodne (npr. slovenska manjšina v Italiji in italijanska v Sloveniji), regionalne (npr. Furlani v Italiji) in migrantske skupnosti. Pojem "avtohtonosti« manjšine je relevanten izključno takrat, ko govorimo o formalnopravnem statusu jezika, torej o zakonskem okviru zaščite skupnosti govorcev, ki največkrat temelji na načelu »zgodovinske prisotnosti« dane skupnosti na nekem območju.
} 
in dijaki izhajajo, oz. da je v tem okolju prisoten vsaj do take mere, da omogoča ustrezno izpostavljenost različnim sporazumevalnim praksam (Hickey 2001). Izhajati iz teh aksiomatskih predpostavk pomeni načrtovati pouk, ki bo docela zrcalen pouku večinskega jezika na danem območju, kar ima sicer močan simbolni pomen in verjetno tudi določeno politično težo, ni pa nujno, da ustreza dejanskim potrebam govorcev.

Več analiz stanja med Slovenci v Italiji je pokazalo, da slovenščina za pomemben delež učencev in dijakov šol s slovenskim učnim jezikom ni prvi, primarni ali prevalentni jezik (Bogatec 2015); poleg tega je prisotnost slovenščine v okolju tolikšna in taka, da ne zagotavlja ustrezne izpostavljenosti govorcev različnim rabam jezika (Mezgec 2015). Ker je torej - če malce poenostavimo - slovenščina res učni jezik, ni pa tudi (prevalentni) jezik družine, socializacije in okolja nasploh - se že dogaja, da so govorci bolj vešči rabe formalnih (knjižnih) zvrsti jezika, ki se jih učijo v šoli, kot pa neformalnih (pogovornih), ki naj bi jih usvajali spontano. V vsakdanjih sporazumevalnih okoliščinah, za katere je knjižni jezik neustrezen (Joseph 1987), zato suvereno uporabljajo ali zgolj in izrazito lokalne različice manjšinskega jezika7 ali večinski jezik (Pertot, Kosic 2014). Do procesov zamenjave jezika torej ne prihaja - kot je doslej ugotavljala sociolingvistika $-\mathrm{v}$ formalnih sporazumevalnih okoliščinah (čemur pravimo klasična diglosija), ampak tudi in celo predvsem v neformalnem sporočanju.

\subsection{Jezikovne semienklave}

Sociolingvistika 20. stoletja je pomemben delež svojih obravnav posvetila odnosom med večinskim (dominantnim) in manjšinskim (podrejenim) jezikom, ki sobivata na nekem geografskem območju; prav to sobivanje je

\footnotetext{
$7 \mathrm{~V}$ prispevku raje uporabljam termin lokalne različice kot lokalna narečja, in sicer iz dveh razlogov. Prvič zato, ker se želim izogniti ideološki percepciji narečja kot (edinega) »avtentičnega «, »čistega « in "pravega « jezika; drugič zato, ker želim izpostaviti prisotnost pojavov jezikovnega stikanja predvsem $\mathrm{v}$ formalnih zvrsteh jezika, npr. $\mathrm{v}$ knjižnem jeziku, $\mathrm{v}$ strokovnih besedilih in celo $\mathrm{v}$ pravno-upravni terminologiji. Vse te rabe namreč govorci percipirajo kot lokalno nezaznamovane.
} 
namreč veljalo za problematično, sporno ali splošno kritično (Berruto 2009; Susič, Janežič, Medeot 2010). Danes pa se v Evropi, in sicer specifično na področju t. i. avtohtonih nacionalnih manjšin, kot kritična vzpostavlja (še) druga relacija, ki je doslej veljala za samoumevno in neproblematično: gre za relacijo znotraj kontinuuma danega jezika, in sicer med njegovim centrom in skrajno periferijo (Sanchez-Stockhammer 2012). V slovenskem jezikovnem kontinuumu govorimo npr. o odnosu med t.i. matico (Slovenijo) in t.i. zamejstvom ali zamejstvi, torej območji naselitve avtohtonih slovenskih manjšin v Italiji, Avstriji, na Hrvaškem in Madžarskem.

Nastajanje jezikovnih otokov (enklav), ki so bili doslej v sociolingvistiki znani predvsem pri obravnavi zdomskih oz. migrantskih skupnosti (Myers-Scotton 2002; Schmid 2005; Benmamoun, Montrul, Polinsky 2010), je danes aktualen pojav tudi v zamejstvih, na območjih, ki so geografsko neposredno povezana $\mathbf{s}$ t. i. matico, kjer je dani jezik (npr. slovenščina) večinski, prevalenten ali celo dominanten. Hipoteza, ki jo postavljamo, je, da se skupnost govorcev manjšinskega jezika v zamejstvu distancira in ločuje od matice - in to prav v času, ko bi padec meje, hitrejše prometne povezave in nove tehnologije prej sugerirale procese $\mathrm{v}$ obratni smeri.

Distanciranje in ločevanje dveh sicer geografsko bližnjih skupnosti - torej nastajanje nekega jezikovnega "polotoka « - lahko opazimo pri analizi nekaterih jezikovnih pojavov, ki so povsem slični tistim, ki smo jih doslej opažali pri jezikovnih otokih (Benmamoun, Montrul, Polinsky 2010; Auer, Schmidt 2010). Ta pojav je tesno povezan $\mathrm{z}$ inverzno diglosijo, ki smo jo obravnavali v prejšnjem razdelku. Govorci manjšinskega jezika na jezikovnem polotoku razvijajo nekatera jezikovna znanja v obeh jezikih - večinskem in manjšinskem - svoje sporazumevalne zmožnosti in veščine $\mathrm{v}$ konkretnih vsakdanjih sporazumevalnih okoliščinah pa samo v večinskem jeziku. Ena od posledic tega je postopno opuščanje manjšinskega jezika, ki ga govorci ne obvladajo do take mere, da bi ga lahko uporabljali $\mathrm{v}$ potencialno vseh sporazumevalnih okoliščinah. 
Manjšinski jezik postaja zgolj dediščinski jezik, torej jezik, ki ga skupnost uporablja v nekaterih pretežno obrednih (ritualiziranih) okoljih, ne pa tudi v vsakdanjem neformalnem sporočanju (Kelleher 2010). Za mnoge dediščinske jezike je celo značilno, da imajo govorci do njih na splošno zelo pozitiven odnos, da jih visoko cenijo in da jim pripisujejo velik simbolični pomen. Kljub temu pa je sporazumevalna zmožnost teh govorcev v manjšinskem jeziku, ki je zgolj dediščinski, nizka; omejena je predvsem na nekaj kontekstov, ki sicer niso nujno »manj prestižni«, so pa glede na celoto vseh življenjskih sporazumevalnih položajev gotovo količinsko obrobni.

V takih okoliščinah govorimo o neekvivalentni dvojezičnosti. Če primerjamo sporazumevalno zmožnost govorcev jezika v okolju, kjer je ta manjšinski oz. neprevalentnen, s sporazumevalno možnostjo govorcev istega jezika v okoljih, kjer je ta večinski, prevalenten ali celo dominanten, opažamo bistvena odstopanja. Ne samo, da so manjšinski govorci jezika manj suvereni v različnih sporazumevalnih okoliščinah; tudi njihov idiom se razlikuje od siceršnjega kontinuuma, pri čemer je pojavnost teh odstopanj višja in tudi drugačna $\mathrm{v}$ primerjavi z običajnimi odstopanji znotraj nekega jezikovnega kontinuuma (Grgič 2016c in 2016d). Za dediščinske jezike je na primer - poleg drugih pojavov jezikovnega stikanja - značilna raba arhaizmov, nepoznavanje novejših sporazumevalnih praks $\mathrm{v}$ danem jeziku, razširjena releksifikacija (torej raba leksemov prevalentnega jezika). Ta odstopanja od ustaljenega standarda ${ }^{8} \mathrm{v}$ danem jeziku sicer niso »problematična « sama po sebi - taka postanejo v trenutku, ko zavirajo suvereno rabo jezika in sporazumevanje govorcev z različnih območij ter pospešujejo uvajanje vzporednih standardov na področjih, kjer se zahteva načelna doslednost in enoznačnost - na primer $\mathrm{v}$ strokovni terminologiji. Ko postane lokalni idiom edina zvrst jezikovnega kontinuuma, ki jo govorci še uporabljajo ali celo razumejo, se lahko namreč

\footnotetext{
$8 \mathrm{~V}$ prispevku skušam tudi terminološko izpostaviti razliko med standardom kot ustaljeno jezikovno prakso (t. i. splošnim pogovornim jezikom) in normo kot konvencionalno in vsaj delno arbitrarno kodifikacijo jezika (t. i. knjižnim jezikom).
} 
sprožijo nadaljnji procesi, ki presegajo čisto jezikovno raven in postajajo socialni ali celo politični pojav.

\subsection{Jezikovni separatizem/secesionizem}

Klasična sociolingvistika 20. stoletja je obširno obravnavala pojave zamenjave, izgube ali smrti jezika. V novih, vse zapletenejših kontekstih pa na bolj izpostavljene jezike in idiome prežijo nove »nevarnosti« - vzroki in posledice jezikovnih trendov, ki jih trenutno spremljamo, so drugačni (Cooper 1989; Berruto 2009).

Pomanjkanje možnosti rabe manjšinskega jezika v bolj »prestižnih okoljih « oz. $\mathrm{v}$ formalnih sporazumevalnih položajih ni edini vzrok diglosije, kot smo videli zgoraj. V novih okoliščinah, ki nastajajo po ureditvi formalnopravnega statusa manjšinskih jezikov (Coulmas 1991), opažamo predvsem pomanjkanje potrebe po rabi jezika v neformalnih, vsakdanjih okoljih, tistih, ki jih npr. strukturirana didaktična okolja ne morejo povsem replicirati (Mougeon, Bniak 1991). Zdi se, da ko manjšinske skupnosti pridobijo šole, medije in pravico do rabe svojega jezika v javni upravi, postanejo ta okolja (edini?) prostor, v katerem se manjšinski jezik sicer »ohranja«, a nikakor ni rečeno, da se tudi »razvija«; pa tudi razvoj, kolikor ga pač je, včasih poteka povsem ločeno od razvoja primerljive zvrsti v okoljih, kjer dani jezik »nemanjšinski« - torej večinski, prevalenten ali celo dominanten (Schmid 2005).

Nerazvitost jezikovnih veščin in sporazumevalnih spretnosti po eni strani, po drugi pa razvijanje in uveljavljanje vzporednih terminoloških in »poljudnoterminoloških « standardov lahko privede tudi do uporabe izključno lokalnih različic ali do ustvarjanja vzporednih standardov in, v končni fazi, do novih jezikovnih mešanic, ki postanejo edini sporazumevalni standard skupnosti (Auer, Schmidt 2010; Auer 2011). Tam, kjer se skupnost identificira z jezikom, lahko predstavlja neuravnoteženo razvijanje skoraj izključno lokalnih idiomov - tudi mešanic - začetek procesov t.i. jezikovnega secesionizma oz. separatizma. 
O jezikovnem separatizmu ali secesionizmu govorimo takrat, ko se neka (mikro)skupnost ne identificira več z jezikovnim kontinuumom, ampak samo še z eno njegovo izrazito lokalno različico. ${ }^{9}$ To različico skupnost dojema kot povsem samostojno jezikovno tvorbo (torej kot »jezik « in ne kot narečje oz. različico znotraj nekega obsežnejšega kontinuuma), sebe pa kot samostojno, ločeno skupino govorcev (Cooper 1989; Kordić 2010). Gre, skratka, za diskurzivno konstituiranje t.i. Abstand jezika na podlagi razlik znotraj jezikovnega kontinuuma, ki sčasoma izgubljajo status variacije in pridobivajo status vzporednega standarda. Do teh premikov prihaja na primer pri poimenovanju idioma (npr. »rezijanščina « namesto »rezijansko narečje«), pri izdajanju enojezičnih priročnikov, ki imajo status normativnega vira (npr. slovnica), pri osnovanju dvojezičnih virov, ki obravnavajo na eni strani lokalni idiom nekega jezikovnega kontinuuma, na drugi pa strani pa knjižni/standardni idiom drugega jezikovnega kontinuuma (npr. rezijanskoitalijanski slovar), pri rabi lokalnih različic v kontekstih, kjer se pričakuje raba nelokalnih (standardnih, knjižnih ...) različic, itd.

Na območju naselitve slovenske manjšine v Italiji opažamo take primere praks konstituiranja mikro skupnosti, ki se identificirajo zgolj z lokalnimi idiomi in jih percipirajo kot samostojne jezikovne kontinuume, v Reziji in v Benečiji, sicer pa je pojav v sami Evropi kar pogost (Cooper 1989, Trudgill 1992; Kordić 2010).

\section{4 Šolanje kot (ne)popolna potopitev}

Med ideološkimi stališči, ki prej negativno kot pozitivno učinkujejo na procese usvajanja in učenja jezika ter na razvijanje veščin in spretnosti $\mathrm{v}$ danem jezikovnem kontinuumu, je tudi predpostavka, da lahko manjšinske šole izobražujejo po načelu t. i. popolne potopitve v jezikovno okolje (Baetens Beardsmore 1993). Raziskave, ki so jih opravili pri nekaterih drugih manjšinah (Cummins 1989; Valdes 1997; Hickey 2001) že kažejo, da so te predpostavke

\footnotetext{
9 Pri tem se opiram na klasično sociolingvistično razlikovanje Abstandt/Ausbau jezikov, ki pa ga pojmujem kot diskurzivni konstrukt skupnosti govorcev.
} 
povsem nerealne, prav tako pa so nerealni tudi rezultati in cilji, ki jim jih skupnost pripisuje (Hickey 2001). Na podlagi teh raziskav, ki sicer niso bile izvedene na območju naselitve slovenske skupnosti v Italiji, ampak v drugih manjšinskih okoljih (Mougeon, Bniak 1991), smo poseben razdelek spletne platforme SMeJse namenili izvirnemu učnemu gradivu, ki nastaja v okviru istoimenskega projekta.

Učne enote za spodbujanje učenja in usvajanja jezikovnih znanj ter razvoja jezikovnih veščin $\mathrm{v}$ slovenskem jeziku bodo $\mathrm{v}$ prvi fazi namenjene starostni skupini 12- do 15-letnih učencev in dijakov, ki obiskujejo šole s slovenskim učnim jezikom v Italiji. V nadaljnjih fazah bodo sorodna gradiva oblikovana tudi za druge starostne skupine. Vsebinsko bodo gradiva obravnavala teme in predmetnosti, ki niso vključene v običajne učne načrte za pouk jezika, ki je sicer učni jezik šole in za katerega se ideološko predpostavlja, da je prvi in primarni jezik učencev in dijakov. Za razliko od drugih učbenikov bomo namreč v tem primeru izhajali iz ugotovitev (Bogatec 2011; Pertot, Kosic 2014; Mezgec 2015; Grgič 2016 c in 2016d), da:

- učni jezik šole (slovenščina) ni nujno prvi in primarni jezik učencev in dijakov, ki obiskujejo šolo s slovenskim učnim jezikom v Italiji;

- učni jezik šole (slovenščina) ni nujno jezik okolja, v katerem ti učenci in dijaki živijo; to pomeni, da učenci in dijaki niso dovolj in ustrezno izpostavljeni raznolikim rabam jezika in torej nimajo vedno možnosti, da bi jezikovne prvine usvajali spontano (izven didaktično strukturiranih okolij);

- je izpostavljenost učnemu jeziku (slovenščini) izven didaktično strukturiranih okolij kakovostno in kolikostno omejena na določene kontekste, ki so v večji meri ritualizirani: proslave, kulturne in umetniške prireditve, javni govori ob protokolarnih dogodkih ...;

- prihaja na območju, kjer se nahajajo omenjene šole, do izrazitih splošnih in specifičnih pojavov jezikovnega stikanja, ki zadevajo vse 
ravni in ravnine jezika (konvergenca, kalki, releksifikacija, paronimi ...);

- je območje, kjer se nahajajo omenjene šole, z jezikovnega vidika izpostavljeno, kar pomeni, da prihaja do socio- antropo- in psiholingvističnih trendov, ki ne vplivajo samo na jezikovne pojave, ampak tudi na percepcijo, didaktiko in položaj jezika.

V sklopu projekta SMeJse se je oblikovala delovna skupina, ${ }^{10}$ ki je vzpostavila metodološke temelje, poiskala praktične rešitve in poskrbela za testiranje oz. implementacijo gradiv, kar naj bi predstavljalo primerno izhodišče za nadaljnjo nadgradnjo projekta.

\subsection{Stigmatizacija neproblemov in nereševanje problemov}

Ob koncu naj omenimo še ključno vlogo, ki jo imajo pri oblikovanju jezikovnih politik in načrtovanja ${ }^{11}$ percepcije in reprezentacije govorcev ter konstrukt prepričanj, ki mu pravimo jezikovna ideologija (Joseph 1987; Cooper 1989; Davies 2003; Van Dijk 2008).

Skupnosti govorcev oblikujejo kompleksne sisteme percepcij jezika in predstav o jeziku in jezikih, ki jih uporabljajo oz. s katerimi prihajajo v stik. Ti sistemi vzpostavljajo tudi nekatere identitetne opcije skupnosti (Petrović 2006). O jezikovni ideologiji govorimo specifično takrat, ko nekdo, ki ima močnejši položaj, posreduje svoj sistem idej, vrednot in verovanj z namenom, da ta položaj ohrani. $\mathrm{V}$ takem kontekstu se ideje, vrednote in verovanja v diskurzu pojavljajo kot »obča znanja « in »splošna vedenja « (Van Dijk 2012) - meja med znanstveno epistemologijo in etično/moralno opredelitvijo je povsem zabrisana. Za razliko od znanstvenih hipotez ali teorij ideološka jedra ne

${ }^{10}$ Več podatkov o avtorjih posameznih učnih enot in gradiv je objavljenih na spletni strani.

${ }^{11} \mathrm{~S}$ pojmom načrtovanje (language planning) mislim na načrtovanje statusa, korpusa in usvajanja jezika (status, corpus and acquisition planning) kot osrednjih temeljev jezikovne politike. 
potrebujejo preverljive podlage ter jo včasih celo zavračajo, včasih pa skušajo podrediti lastnim potrebam. Cilj ideologije namreč ni razumevanje nekega pojava ali opredeljevanje nekega pojma, ampak apriorno upravičevanje praks, ki vodijo $\mathrm{v}$ vzpostavljanje odnosov moči, dominacije/podrejenosti, vključenosti/izključenosti itd. (Grgič 2016).

Eden od temeljnih postopkov »ideologizacije« jezika je ignoriranje ali podcenjevanje nekaterih pojavov, ki so za jezikoslovne vede relevantni, in fokusiranje ali precenjevanje drugih pojavov, ki so sicer povsem marginalni oz. nerelevantni za razumevanje družbenih in kulturnih ali jezikovnih procesov (MacIntyre et al. 1997; Schmidt 2010). Hierarhija se v tem primeru vzpostavlja mimo znanstvenih kriterijev, predvsem kot oblika moralnega/etičnega vrednotenja posameznih jezikovnih praks (Van Dijk 2008).

Analiza diskurzov o jeziku, ki jih oblikuje skupnost govorcev slovenskega jezika v Italiji, je na primer pokazala (Grgič 2016d), da se pri obravnavi jezikovnih pojavov, ki naj bi »ogrožali jezik«, v javnem diskurzu stigmatizirajo nekatere rabe, ki so sicer v procesih folklorizacije, okamnitve, zamenjave/opuščanja in nazadnje izgube jezika znotraj neke skupnosti povsem nerelevantne. Po drugi strani pa se ne samo tolerirajo, ampak celo zagovarjajo in promovirajo rabe in izbire, ki so v perspektivi ohranjanja rabe jezika, njegove revitalizacije in razvijanja lahko sporne (Grgič 2016c). Ločnico med enimi in drugimi predstavlja družbeni status govorcev: višji je, bolj so jezikovne prakse percipirane kot sprejemljive, neoporečne ali celo »vzorne« (Edwards 1996). Tipičen primer tega je strokovna terminologija nekaterih področjih, ki veljajo za »višja« - na primer v podjetništvu, javni upravi, pravu, zdravstvu ali v šolstvu. Tu se nekatere terminološke izbire, ki sicer niso dosledne s standardno terminologijo danega področja, uveljavljajo kot vzporedni standard in sploh niso percipirane kot lokalna nestandardna različica.

Problem vzporednih standardov je dvojne narave: prvič gre za terminološko vprašanje, saj je terminologija ena redkih jezikoslovnih ved - če že ne edina -, 
pri kateri je kodifikacija potrebna in nujna. Drugič pa gre za sociolingvistično vprašanje, saj je terminološki standard eden ključnih izzivov jezikovnega načrtovanja (Nahir 2003).

\section{SKLEP: SPLETNA PLATFORMA SMeJse IN NJEN POTENCIALNI RAZVOJ}

V prispevku sem obravnavala nekatere metodološke in raziskovalne izzive, ki so se porodili ob načrtovanju spletne platforme SmeJse. Posebej sem se zaustavila ob nekaterih vozliščih, ki kažejo na velike premike, do katerih je prišlo na področju interdisciplinarnih jezikoslovnih ved na prehodu med 20. in 21. stoletjem, tudi glede specifičnih vprašanj, povezanih z manjšinskimi jeziki.

Priprava spletne platforme SMeJse se je začela julija 2016 in je trenutno v sklepni fazi. Platforma je bila javnosti predstavljena novembra 2017, nekateri razdelki pa so še v fazi implementacije. Trenutno so na spletni platformi dostopne:

- povezave do obstoječih virov in tehnologij za slovenski jezik (http://www.smejse.it/orodjarna/),

- igre, vprašalniki in poljudni testi za različne ciljne skupine (http://www.smejse.it/ elements_trashed/izpitisce/),

- nekatere učne enote za vrtce, osnovno in srednjo šolo $s$ hiperpovezavami do obstoječih gradiv in izvirnimi delovnimi listi (http://www.smejse.it/ucilnica/),

- poljudnoznanstvene objave (blogi) o italijansko-slovenskem jezikovnem stikanju, didaktiki manjšinskih jezikov, dvojezičnosti, lažnih mitih o jeziku (http://www.smejse.it/spletna-predavalnica/),

- povezave do avdio (https://www.smejse.it/avdioteka/) in video (http://www.smejse.it/blogvideo/) gradiva ter

- povezave do obstoječih jezikovnih svetovalnic (http://www.smejse.it/spletna-jezik-svetovalnica/).

Platforma je povezana tudi $\mathrm{z}$ družbenima omrežjema Facebook [102] 
(https://www.facebook.com/SMeJse- Sloven\%C5\%A1\%C4\%8Dina-kot-manj\%C5\%A1inski-jezik145658222839724/) in Twitter (https://twitter.com/SMeJse_).

V zadnjem letu so bile opravljene te dejavnosti:

1. analiza stanja: razgovori z nosilci interesov (dijaki, profesorji, starši, vzgojitelji, trenerji ...) in anonimno testiranje stopnje razvoja jezikovnih veščin učencev in dijakov v slovenskem jeziku;

2. zbiranje informacij o stanju in ukrepih pri drugih primerljivih manjšinah oz. skupnostih govorcev;

3. zbiranje gradiv, ki so že nastala v na območju naselitve slovenske manjšine v Italiji;

4. pregled, izbor in obdelava gradiv;

5. izdelava treh poskusnih didaktičnih učnih enot;

6. testiranje gradiv med poukom oz. med obšolskimi dejavnostmi; popravki in dopolnitve;

7. objava gradiv na spletni strani.

Projekt se bo nadaljeval tudi v letu 2018, seveda ob ustreznem financiranju in institucionalni podpori.

Prvi poskusni sklop gradiv (delovnih listov) bomo dopolnili z dodatnimi enotami (končni cilj je izdelava 15 učnih enot) za različne starostne skupine učencev in dijakov (6-9, 9-12 in 15-18 let), s priročniki in gradivom, namenjenim drugim ciljnim skupinam (predšolski otroci, odrasli, učitelji, prevajalci, novinarji ...). Vsi priročniki in gradiva bodo zasnovani kot spletna orodja, ki se stalno posodabljajo, tudi v povezavi z razpoložljivimi viri za slovenski jezik.

Platforma naj bi se razvijala $\mathrm{v}$ smislu vedno večje in bolj razširjene interaktivnosti: vzpostavila naj bi se svetovalnica, izrecno namenjena pojavom italijansko-slovenskega jezikovnega stikanja, na podlagi izkušenj govorcev pa bi se zbirali primeri jezikovne rabe in sporazumevalnih praks. Za tovrstni razvoj platforme pa bomo seveda potrebovali ustrezno raziskovalno, stokovno in 
tehnično infrastrukturo.

Tudi v luči tovrstne popularizacije spletnih gradiv se nam zdi potrebno, da se v prihodnjih letih dodelajo in na novo izdelajo prosto dostopni viri za slovenski jezik, ki naj se nadgradijo s specifičnimi informacijami o rabi jezika na območjih jezikovnega stikanja.

\section{LITERAT URA}

Auer, P. (2011): Dialects vs. Standard. A typology of scenarios in Europe. Kortmann, B., van der Auwera, J., eds.: The Languages and linguistics of Europe. Berlin - Boston: De Gruyter Mouton.

Auer, P., Schmidt, J., eds., (2010): Language and Space. An International Handbook of Linguistic Variation. Volume 1: Theories and Methods. Berlin - New York: Walter de Gruyter.

Baetens Beardsmore, H. (1993): European models of bilingual education. Clevedon: Multilingual Matters.

Baker, C. (2003): Foundations of bilingual education and bilingualism. Clevedon, Buffalo, Toronto, Sydney: Multilingual Matters.

Benmamoun, E., Montrul, S., and Polinsky, M. (2010): White Paper: Prolegomena to Heritage Linguistics. Harvard University, 12: 26-43.

Berruto, G. (2009): Confini tra sistemi, fenomenologia del contatto linguistico e modelli del code switching. Iannaccaro, G., and Matera, V., eds., La lingua come cultura. Torino: UTET.

Bogatec, N. (2015): Šolanje v slovenskem jeziku v Italiji. Razprave in gradivo: revija za narodnostna vprašanja / Treatises and documents: journal of ethnic studies, 74: 5-21.

Bogatec, N. ed. ( 2004): Slovene: The Slovene Language in Education in Italy. Ljouwert: Mercator education. 
Bourdieu, P. (1977): L'économie des échanges linguistiques. Langue française, 34 (1): $17-34$.

Canagarajah, A. S., ed. (2005): Reclaiming the local in language policy and practice. Mahwah (NJ): Lawrence Erlbaum.

Carli, A., Sussi, E., and Kaučič-Baša, M. (2002): History and Stories. Identity Construction on the Italian-Slovenian Border. Meinhof, ed., Borders in Europe. Border Region Studies. Aldershot: Ashgate.

Cook, V. (2008): Second Language Learning and Language Teaching. London: Hodder Education Company.

Cooper, R. L. (1989): Language planning and social change. Cambridge, New York: Cambridge University Press.

Coulmas, F. (1991): A Language Policy for the European Community. Berlin New York: Mouton de Gruyter.

Cummins, J (1989): Empowering minority students. Sacramento: CABE.

Davies, A. (2003): The native speaker: myth and reality. Clevedon - Buffalo Toronto - Sydney. Multillingual Matters.

Edwards, J. (1996): Language, Prestige, and Stigma. Contact Linguistics. New York: de Gruyter.

Formigari, L. (2001): Il linguaggio. Storia delle teorie. Roma-Bari: Laterza.

Grgič, M. (2016): Jezik : sistem, sredstvo in simbol : identiteta in ideologija med Slovenci v Italiji. Trst: Slovenski raziskovalni inštitut.

Grgič, M. (2016b): The identification and definition of the minority community as an ideological construct: the case of Slovenians in Italy. Razprave in gradivo: revija za narodnostna vprašanja / Treatises and documents: journal of ethnic studies, 77: 87-102.

Grgič, M. (2016c): Alcuni aspetti di prassi e politiche linguistiche (implicite) 
nella comunità slovena in Italia. Europa orientalis, 35: 531-541.

Grgič, M. (2016d): Lo sloveno in Italia: fenomeni di contatto linguistico tra pragmatica, percezione e ideologia. Ricerche slavistiche, 60: 387-415.

Grgič, M. (2017): Italijansko-slovenski jezikovni stik med ideologijo in pragmatiko. Jezik in slovstvo, 62 (1): 89-98.

Hickey, T. (2001): Mixing beginners and Native Speakers in Minority Language Immersion: Who is Immersing Whom? The Canadian Modern language Review, 57 (3): 443-474.

Hoff, E., et al., (2012): Dual language exposure and early bilingual development. Journal of Child Language, 39(1): 1-27.

Hymes, D. (1966): Two types of linguistic relativity. Bright, W.Sociolinguistics. The Hague: Mouton: 114-158.

Jagodic, D., and Čok, Š., eds. (2013): Med drugim in tujim jezikom. Poučevanje in učenje slovenščine pri odraslih v obmejnem pasu Furlanije - Julijske krajine. Trst: Slovenski raziskovalni inštitut.

Joseph, J. E. (1987): Eloquence and Power: The Rise of Language Standards and Standard Languages. New York: Blackwell.

Kaučič-Baša, M., (2004): Ohranjanje slovenščine pri Slovencih na Tržaškem i Goriškem: nekaj elementov za tezo o vzrokih opuščanja manjšinskih jezikov. Slovenščina v šoli, 9 (3): 12-19.

Kaučič-Baša, M., (1997): Where do Slovenes speak Slovene and to whom? : minority language choice in a transactional setting. International journal of the sociology of language, 124: 51-73.

Kelleher, A. (2010): What is a heritage language? Center for Applied Linguistics. Available at: http://www.cal.org/heritage/pdfs/briefs/What-is-aHeritage-Language.pdf. 9. 2017).

Kordić, S. (2010): Jezik i nacionalizam. Zagreb: Rotulus Universitas. 
MacIntyre, P. D., et al. (1997): Biases in Self-Ratings of Second Language Proficiency: The Role of Language Anxiety. Language Learning, 47 (2): $265-287$.

Meisel, J. (2007): The weaker language in early child bilingualism: Acquiring a first language as a second language? Applied Psycholinguistics 28 (3): 495-514.

Mezgec, M. (2012): Funkcionalna pismenost v manjšinskem jeziku: primer slovenske manjšine v Italiji. Koper: Univerzitetna založba Annales.

Mezgec, M. (2015): Raziskava o jezikovni pokrajini na naselitvenem območju slovenske skupnosti v Italiji: raziskovalno poročilo. Trst: Slovenski raziskovalni inštitut.

Mougeon, R., and Bniak, E. (1991): Linguistic consequences of language contact and restriction. The case of Franch in Ontario, Canada. New York: Oxford University Press.

Myers-Scotton, C. (2002): Contact Linguistics. Bilingual Encounters and Grammatical Outcomes. Oxford: Blackwell.

Myhill, J. (2003): The native speaker, identity and the authenticity hierarchy. Language Sciences, 25 (1): 77-97.

Nahir, M. (2003): Language Planning Goals: A Classification. Paulston, Ch., and G. Tucker, R., Sociolinguistics: The Essential Readings. Oxford: Blackwell.

Pertot, S., (2011a): Identitetne spremembe med Slovenci v Italiji v družinah učencev šol s slovenskim učnim jezikom v Italiji. Razprave in gradivo: revija za narodnostna vprašanja, 66: 24-43.

Pertot, S., (2011b): The language transmission goals of the Slovene minority schools in Italy: a reality check. Cultural education and civil society: how can languages contribute? Leeuwarden / Ljouwert: Mercator 
European Research Centre on Multilingualism and Language Learning, Fryske Akademy: 26.

Pertot, S., Kosic, M. (2014) Jeziki in identitete v precepu: mišljenje, govor in predstave o identiteti pri treh generacijah maturantov šol s slovenskim učnim jezikom v Italiji. Trst: Slovenski raziskovalni inštitut.

Phillipson, R. (2003): English-only Europe? Challenging Lanugage Policy. London-New York: Routledge.

Piller, I. (2016): Linguistic Diversity and Social Justice. An Introduction to Applied Sociolinguistics. Oxford - New York: Oxford University Press.

Sanchez-Stockhammer, Ch. (2012): Hybridization in Language.

Stockhammer, Ph. W., ed., Conceptualizing Cultural Hybridization. A Transdisciplinary Approach. Heidelberg: Springer Verlag.

Saxena, M. (2014): "Critical diglossia" and "lifestyle diglossia": development and the interaction between multilingualism, cultural diversityand English. International Journal of the Sociology of Language, 225: 91112.

Schmid, S., (2005): Code-switching and Italian Abroad. Reflections on Language Contact and Bilingual Mixture. Rivista di linguistica 17 (1).

Schmidt, R. (2010): Attention, awareness, and individual differences in language learning. Chan, W. M., et al., eds.: Proceedings of CLaSIC 2010, National University of Singapore, Centre for Language Studies Singapore: 721-737.

Strani, P., ed. (2017): Učni načrt za slovenski jezik. Trst: Državni izobraževalni zavod Jožef Štefan.

Susič, E., Janežič, A., and Medeot. F. (2010): Indagine sulle comunità linguistiche del Friuli Venezia Giulia: tutela e normativa. Udine: Regione FVG. 
Thordardottir, E. (2011): The relationship between bilingual exposure and vocabulary development Article. International Journal of Bilingualism, 15 (4): 426-445.

Tollefson, J. W. (2000): Language ideology and language education. Shaw, J., et al., eds.: Partnership and interaction. Proceedings of the Fourth International Conference on Language and Development. Bangkok: Asian Institute of Technology.

Trudgill, P. (1992): Ausbau sociolinguistics and the perception of language status in contemporary Europe. International Journal of Applied Linguistics, 2 (2): 167-177.

Trudgill; P. (2004): Glocalisation and the Ausbau sociolinguistics of modern Europe. Duszak, A. - Okulska, U., eds.: Speaking from the margin: Global English from a European perspective. Frankfurt: Peter Lang: $35-49$.

Edwards, J. (1996): Language, Prestige, and Stigma. Contact Linguistics. New York: de Gruyter.

Unsworth, S., (2014): Comparing the Role of Input in Bilingual Acquisition Across Domains. Grüter, T. - Paradis, J., eds: Input and Experience in Bilingual Development. Amsterdam -Philadelphia: John Benjamins Publishing Company: 181-201.

Valdes, G. (1997): Dual-language immersion programmes: a cautionary note concerning the education of language-minorty students. Harvard Educational Review, 71: 391-429.

Van Deusen-Scholl, N. (2003): Toward a definition of heritage language: Sociopolitical and pedagogical considerations. Journal of Language, Identity, and Education. 2: 211-230.

Van Dijk, T. A. (2008): Discourse and Power. Houndsmills: PalgraveMacMillan. 
Van Dijk, T. A., (2012): Discourse and Knowledge. Gee, J. P., and Handford, M., eds.: Handbook of Discourse Analysis. London: Routledge.

Vidau, Z. (2013): The legal protection of national and linguistic minorities in the Region of Friuli Venezia Giulia: a comparison of the three regional laws for the "Slovene linguistic minority", for the "Friulian language" and for the "German-Speaking minorities". Razprave in gradivo: revija za narodnostna vprašanja / Treatises and documents: journal of ethnic studies, 71: 27-52. 


\section{THEORETICAL ASSUMPTIONS AND \\ METHODOLOGICAL FRAMES FOR A USER- \\ FRIENDLY WEB PLATFORM: THE SMEJSE \\ PROJECT (SMiLe - SLOVENIAN AS A MINORITY LANGUAGE)}

This paper aims to present some theoretical and methodological issues related to the online portal SLOVENŠČINA KOT MANJŠINSKI JEZIK - SMeJse / SLOVENIAN AS A MINORITY LANGUAGE - SMiLe where existent tools, materials and information for the development of linguistic skills and abilities in Slovenian are collected. The platform was established by SLORI - Slovenski raziskovalni inštitut / Slovenian research institute of Trieste, Italy, and the Dijaški dom S. Kosovela / Slovenian student's center of Trieste, Italy. The purpose of the portal is to stimulate different usages of the current Slovenian language in the Slovenian-Italian contact area, particularly in Italy, with the aim of assuring high communication proficiency in all kinds and varieties of the Slovenian language (the so called "equilingualism"), a balanced bilingualism and also the development of lects, still within the Slovenian linguistic continuum.

Specific language policies are particularly successful for the development of linguistic skills which enable proficiency in the minority language, as well as equilingualism and balanced bilingualism among the speakers of the minority group. Such policies are based on the implementation of measures for an increased exposure to different language uses and on the creation of the need of language use in circles and situations where compensatory strategies are unsuitable. The portal is based on the newest linguistic, sociolinguistic and psycholinguistic studies concerning the Slovenian language in Italy, on the Slovenian-Italian language contact, and the acquisition of the minority language. An analysis of the status of the Slovenian language in Italy, its perception and its phenomena, as well as the overview of some language policies and methodological frames, has shown a gap between the existent tools and the needs of the community of speakers.

Keywords: minority languages, Slovene language in Italy, language skills development; balanced bilingualism; language contact 
To delo je ponujeno pod licenco Creative Commons: Priznanje avtorstvaDeljenje pod enakimi pogoji 4.o Mednarodna.

This work is licensed under the Creative Commons Attribution-ShareAlike 4.0 International.

https://creativecommons.org/licenses/by-sa/4.o/

(c) (1) () () 